\title{
LOS EVANGELISTAS \\ EN LA OBRA DE JOSÉ ORTEGA Y GASSET
}

\author{
Luis Miguel Pino Campos \\ Universidad de La Laguna \\ lmpino@ull.edu.es
}

\section{RESUMEN}

José Ortega y Gasset se hizo eco en varios escritos de algunos pasajes de los Evangelios, bien porque estaba exponiendo un tema relacionado con la época de Jesucristo, bien por la coincidencia de varias fuentes que confirmaban la veracidad de un acontecimiento casual como fue una inscripción descubierta a finales del siglo I. Las referencias están incluidas en pasajes de contenido filosófico o histórico, con la característica común de tratar los pasajes evangélicos con escrupulosa objetividad y precisión.

Palabras Clave: José Ortega y Gasset, Evangelios, Jesucristo, Apóstoles, filosofía.

\section{THE EVANGELISTS IN THE WORK OF JOSÉ ORTEGA Y GASSET}

\section{ABSTRACT}

José Ortega y Gasset mentions in several of his writings some Gospel passages, either because he was exposing a subject related to the time of Jesus Christ, or due to the agreement of various sources confirming the truth of a casual event as was the case of an inscription discovered in the late $1^{\text {st }}$ century. The evangelic passages from the references, included in philosophic or historic texts, have always been managed with a thorough treatment and precision.

KeY WORDs: José Ortega y Gasset, Gospels, Jesus Christ, Apostles, philosophy.

\section{INTRODUCCIÓN}

En estudios anteriores nos hemos ocupado de analizar algunos comentarios de José Ortega y Gasset (1883-1955) en torno a la religión, a Dios y a algunas divinidades del mito clásico. En esta oportunidad nos ocuparemos de lo que dice Ortega de los cuatro evangelistas, dado que no deja de sorprender que el filósofo madrileño, quien varias veces recordara su actitud no confesional, aludiera y comentara con su habitual magisterio la importancia que en nuestra cultura y en nuestra vida había tenido y seguía teniendo no ya la aparición del Cristianismo, sino sus Sagradas Escrituras, entendiendo por éstas, no sólo las del Antiguo, sino también las del Nuevo Testamento, Hechos de los Apóstoles, cartas de San Pablo y otros tantos libros 
sagrados, los cuales expresaban la nueva creencia que Jesús de Nazaret había transmitido a sus discípulos con la finalidad de que fuese propagada a todos los pueblos.

Nos proponemos analizar y comentar algunos pasajes recogidos por el filósofo madrileño en sus libros, artículos periodísticos y cartas, en los que se mencionan directa o indirectamente pasajes de los evangelistas, con la finalidad de subrayar la importancia que tales textos tenían en su obra; para ello usaremos la nueva edición de sus Obras completas (Madrid, Taurus, 2004-2010; diez volúmenes).

\section{EL EVANGELIO DE SAN JUAN}

Empezaremos por San Juan Evangelista (ca. 20 d.C.-100-105), al que tantos estudios ha dedicado Juan Barreto Betancort, y sobre el que Ortega y Gasset escribió nueve referencias. Recordemos brevemente unas pinceladas biográficas del apóstol evangelista.

La historia de san Juan se inicia cuando en compañía de su hermano Santiago el Mayor, conoció a Jesús de Nazaret junto al lago Tiberíades; Juan tendría veinte años, cuando Jesús lo llamó para que le siguiera con su hermano Santiago y con Simón, luego llamado Pedro. Se le atribuye la autoría de El Apocalipsis, de tres cartas y del evangelio que lleva su nombre. Juan acompañaría a la madre de Jesús en varios momentos fundamentales de su vida, como fue el de la crucifixión. Según las opiniones de Luis Alonso Schökel y de Juan Mateos es probable que este Evangelio tuviera dos ediciones: la primera hecha por el evangelista Juan, la segunda hecha tras su muerte, realizada seguramente por un discípulo, quien añadió material del mismo evangelista que no había sido incorporado en la primera edición, e intercaló algunos textos de diversas versiones de un mismo episodio o discurso ${ }^{1}$.

\section{LOS PASAJES DE ORTEGA² QUE ALUDEN A SAN JUAN EVANGELISTA}

3.1. Uno de los escritos que José Ortega y Gasset dedicó al asunto de los terrores del año 1000, titulado "La leyenda»", recordaba unas frases del célebre historiador francés Jules Michelet ${ }^{4}$, según las cuales existió una leyenda durante la Edad Media,

\footnotetext{
${ }^{1}$ Véase Luis Alonso Schökel y Juan Mateos (eds.): Nueva Biblia Española. Madrid 1977 (2a edic.). Ediciones Cristiandad, pp. 1648-1649.

${ }^{2}$ Citamos los textos de José Ortega y Gasset por Obras completas. Madrid 2004-2010. Taurus. 10 vols. En adelante, $O C$.

${ }^{3}$ OC. I, pp. 309-314, especialmente p. 311. Se trata del comentario titulado «La leyenda», dentro del apartado titulado "Los terrores del año mil. Crítica de una leyenda» (pp. 63-314), que incluye dos ensayos previos: «Notas. Sobre los legendarios terrores del año mil», y "Las figuras».

${ }^{4}$ París, 21/08/1798 - Hyères, 09/02/1874.
} 
en la que se afirmaba que «el mundo debía acabar en el año 1000 de la Creación»; era una creencia por la que se pensaba que la vida era un caos y que, aunque se aspirase al orden, éste sólo llegaría con la muerte; era una imagen de un mundo sin esperanza, de desdichas sobre desdichas. Se anhelaba salir de la angustia y caer entre las manos de Dios a cualquier precio; la desgarradora trompeta del Arcángel heriría los oídos y en las alturas sonaría una terrible carcajada en medio de los llantos -comentaba Ortega-imitando las escatológicas frases del medievo. La estatuaria de aquella época medieval refleja bien este ambiente de sufrimiento y deformidad y hasta las leyendas del diablo contribuían a una mayor angustia.

Las teorías de Rufino y las interpretaciones de Orígenes y de san Agustín favorecieron una interpretación simbólica no exenta de superstición, lo que en parte explicaba que fuera el Apocalipsis de San Juan uno de los libros más leídos. En efecto, en él hay expresiones que señalan un caos próximo que favorecería la sensación de inquieta inseguridad, como cuando se lee: «Y cuando los mil años fueren cumplidos, Satanás será suelto de su prisión. Y saldrá para engañar a las naciones que están sobre los cuatro ángulos de la tierra, a Gog y a Magog, a fin de congregarlas para la batalla [...]». Gog y Magog eran respectivamente los nombres de un rey y del segundo hijo de Jafet. A prejuicios como éste se añadían palabras puestas en boca de Jesús: hambres, pestes, temblores de tierra y grandes señales en el cielo indicarían el inicio del fin del mundo.

Ortega recordará otros mensajes de escritores del siglo X que favorecían ese temor, como son los casos de Raúl Glaber ${ }^{6}$ y de Adso. El primero comentaba que: «Según la profecía de [San] Juan, Satanás será muy pronto desencadenado, porque se van a cumplir los mil años». ${ }^{7}$ Por su parte, Hermerio Adson ${ }^{8}$ compuso un Libellus

${ }^{5}$ Rufino (345-411) nació cerca de Aquilea y murió en Mesina (Sicilia). En Roma conoció a San Jerónimo y fue bautizado en Aquilea en el 370; había sido instruido en la religión cristiana por Cromacio, más tarde obispo, y por los diáconos Jovino y Eusebio.

${ }^{6}$ Rodolfo Glaber (Borgoña 985 - Auxerre 1047) fue monje y cronista; alumno de Guillermo de Volpiano, pasó por diversos monasterios de Borgoña, hasta que encontró asilo en Cluny, donde en 1047 acabó de redactar Los cinco libros de las historias, en los que ofrecía indicaciones para el período alrededor del año 1000. Escribió también La vida de San Guillermo. Véanse, entre otras, las ediciones de G. Andenna y D. Tuniz (eds.): Rodolfo il Glabro. Storie dell'Anno Mille. I cinque libri delle Storie. Vita dell'abate Guglielmo, (Milán, 1981) y la de de G. Cavallo y G. Orlandi: Rodolfo il Glabro. Cronache dell'Anno Mille. Storie (Milán, 1989).

7 José Ortega y Gasset: «Los terrores del año mil. Crítica de una leyenda. III: La leyenda», en Obras completas, I (1902-1915), p. 311. Madrid 2004. Taurus.

${ }^{8}$ Hermerio Adson (910-992) o Adso Dervensis, nacido en las montañas del Jura, fue abad del monasterio benedictino de Montier-en-Der (Francia) y murió en una peregrinación a Jerusalén. Autor de cinco hagiografías, de las que la más conocida fue la del Anticristo titulada «De ortu et tempore Antichristii, que combinaba exégesis y sibilina ciencia. Esta obra fue copiada muchas veces. Véase Diccionario histórico, ó Biografia universal compendiada. (Barcelona, 1830; edic. de N. Oliva, tomo I, pp. 119-120). 
de Antichristo para la reina Gerberga ${ }^{9}$, en el que negaba que se acercase la llegada del Anticristo y del fin del mundo, y alegaba que no podría llegar antes de que todos los reinos hubieran sido desmembrados del Imperio Romano, al que estaban sujetos; y en aquella época, los reinos del Imperio estaban sometidos al poder de los reyes de Francia, a quienes correspondería la custodia del poder imperial.

En la crónica de Tritemio $^{10}$ (muerto en 1516) se cuenta que en el año 960 el eremita de Thuringia Bernardo, engañado por sus alucinaciones o por algún espíritu extraño, creía que el fin del mundo era inminente. Esta crónica se reeditó en 1690.

Concilios y escritores varios se hacían eco de ese ambiente pesimista ante la llegada del año 1000, considerado el momento para el fin del mundo. Todavía en la Crónica de Guillermo Godel, monje de Limoges, escrita después del año 1124, se mencionaba la toma de Jerusalén por los turcos en el año 1010, y algunos consideraron que aquella toma de la ciudad santa significaría el final.

Superados los siglos siguientes al décimo, la leyenda permaneció larvada en la memoria de algunos textos, sin que alterara realmente la vida cotidiana. Llegados los siglos XVI y XVII hubo un nuevo intento de renacimiento del miliasmo o milenarismo, dado que algunos espíritus teológicos intentaron reavivar aquellas viejas elucubraciones, volviendo a ciertos pasajes de Orígenes y Rufino. Pero ya no se acudía al evangelio de San Juan.

${ }^{9}$ Gerberga (siglo VIII) fue esposa de Carlomán I, rey de los francos, y cuñada de Carlomagno. Su huida al reino lombardo de Desiderio, tras la muerte de su esposo Carlomán, precipitó la guerra entre francos y lombardos, que supuso el final del reino lombardo en el año 774. Casada en segundas nupcias con Desiderio, rey lombardo, éste fue derrotado, por lo que Gerberga y sus dos hijos Adelchis (el mayor, hijo de Carlomán I, franco), y Autchar (el segundo, hijo de Desiderio de Lombardía) fueron recluidos seguramente en casas religiosas. Véase Pierre Riché, Les Carolingiens, une famille qui fit l'Europe. París, $1983\left(1997^{\mathrm{r}}\right)$, edit. Hachette.

${ }^{10}$ Johannes Trithemius (= Johann von Heidenberg; Trittenheim 1462 - Wurzburgo 1516), fue un monje alemán, fundador de la sociedad secreta Sodalitas Celtica; estudió lenguas, matemáticas, astrología y magia de los números; creó un método de codificación polialfabético. Nombrado abad de Sponheim en 1483, fue autor del primer libro sobre esteganografía (ciencia para ocultar mensajes), de nueve obras históricas, un tratado de las siete causas segundas, opúsculos ascéticos, una obra sobre los milagros de la Virgen María, dos libros de homilías y exhortaciones cenobíticas, y una obra contra los maleficios; acusado de ser aficionado a la magia, el emperador Maximiliano I lo invitó en 1505 al castillo de Boppart para someterlo a ocho preguntas de fe. Trithemius respondió con la publicación de su Liber octo questionum en 1511 y más tarde el emperador lo volvió a llamar para que le aconsejara en asuntos políticos. Véase Juan Pablo Quintero, «Apuntes sobre la Esteganografía de Trithemius», Revista Nova et Vetera, Universidad del Rosario, Colombia; ISSN 2422-2216; v. 1, n. 2; marzo 2016; Francisco de Paula Souza de Mendonça Júnior, «A poligraphia de Johannes Trithemius: reflexões acerca das relaçôes entre Esoterismo e política nos séculos XV e XVI», REHMLAC (ISSN 1659-4223) v. 8, 1; may-nov. 2016, pp. 1-23. 


\subsection{LA VIDA EN TORNO: MUERTE Y RESURRECCIÓN}

En diciembre de 1911 escribió Ortega un artículo periodístico ${ }^{11}$, en el que comentaba las impresiones que había recibido cuando visitó París a su vuelta de Alemania. La capital parisina era conocida por «la ciudad de la luz», pero vivía una etapa decadente; sólo la luz parisina sobresalía en aquel ambiente. Ortega no dudó en ir a visitar la casa que el pintor Zuloaga tenía en París ${ }^{12}$. La descripción del piso, situado en la calle Coulaincourt, al que se accedía tras subir una interminable escalera, desanimó en un primer momento al escritor madrileño porque era un modesto aposento, desmantelado y desolado, rudo en medio del lujo parisino. Mas Ortega encontraría algo digno de destacar en aquel desordenado habitáculo: la pintura, mas no la pintura de Zuloaga, sino la del Greco, porque en una de sus paredes aparecía colgada una pintura, al parecer sólo la parte inferior del cuadro del pintor griego, que representaba la Apocalipsis de San Juan Evangelista, acompañado al fondo por cuerpos desnudos y sus mantos al viento; se distinguen diez figuras, además de la del evangelista vestido con amplio ropaje. Zuloaga había encontrado en una casa castellana abandonada esa pintura y la conservaba en el piso de París. El texto reproduce parcialmente un comentario que Ortega repetirá en varias ocasiones, como veremos en los siguientes apartados. Dice así Ortega:

En un aposento modestísimo, desmantelado, y yo diría que en medio del lujo de París, parecen afirmar aquellas cuatro paredes el derecho a la desolación y a la rudeza que se alza en el fondo de todos los cuadros zuloaguescos. Únicamente pendía, en uno de los muros, una pintura: la Apocalipsis del Greco, o mejor dicho, la parte inferior de esta composición que en una de sus correrías por el interior del cuerpo castellano, logró descubrir Zuloaga. Este cuadro, según se desprende del inventario de los bienes del Greco, recientemente descubierto por el señor San Román, debió ser uno de los últimos que pintó Doménico Theotocópuli, y es como una postrera visión de la materia por un espíritu que va a consumirse quemado por sus propios ardores. En primer término, a la izquierda, la enorme figura de San Juan, el viejo virgen, con las manos en alto, en ademán equívoco de espanto y evocación. Y tras él,

${ }^{11}$ Sería publicado en La Prensa (Madrid), 4 de febrero de 1912.

${ }^{12}$ Ignacio Zuloaga Zabaleta (Éibar 1870 - Madrid 1945), pintor español de estilo costumbrista, es autor de retratos de estilo naturalista, influido por Ribera y Goya, en oposición al estilo luminoso y optimista de Sorolla. Era hijo del damasquinador Plácido Zuloaga y sobrino del ceramista Daniel Zuloaga. Se formó en el taller de su padre en Éibar, donde tuvo los primeros contactos con el dibujo y el grabado. Su formación escolar se realizó con los jesuitas en Francia y los completó en Madrid, París y Roma. Zuloaga pasó gran parte de su vida adulta en París, donde se casó con una francesa llamada Valentine Dethomas. Estuvo vinculado con Segovia, donde tuvo un estudio hasta 1913, y desde 1914 con Zumaya, donde inauguró su casa de Santiago Etxea en 1914. En 1921 inauguró también su taller y museo en la misma propiedad. Desde entonces compaginó tres estudios en París, Madrid y Zumaya. 
bajo una gran batalla que riñen en lo alto las nubes, cuerpos desnudos y flameantes, que aspiran a volatilizarse y sumirse en aquel drama aéreo y semiespiritual de los cielos. Y nada más. ¿¿Es necesario más? La Apocalipsis pudiera muy bien ser uno de los mejores cuadros del mundo, porque ante él sentimos, con pavorosa inmediatez, el tema más sencillo y más profundo de la pintura: un poco de materia puesta a arder. ${ }^{13}$

3.3. La misma referencia a San Juan Evangelista la hace Ortega en otro de sus ensayos de 1917, en el que recuerda la visita que hizo en París a la casa de Zuolaga y la sorpresa que le produjo ver solamente un cuadro incompleto del Greco colgado en la pared, al que hemos aludido en el parágrafo anterior. El cuadro fue uno de los últimos pintados por Doménico Theotocópuli. Ortega comenta, repitiendo parcialmente la idea del pasaje anterior:

[El cuadro] es como una postrera visión de la materia por un espíritu que va a consumirse quemado por sus propios ardores. En primer término, a la izquierda, la enorme figura de San Juan, el viejo virgen, con las manos en alto, en ademán equívoco de espanto y evocación. [...] La Apocalipsis es un cuadro ejemplar: ante él sentimos, con pavorosa proximidad, el tema más sencillo y más profundo de la pintura: un poco de materia puesta a arder. ${ }^{14}$

\subsection{DiÁlOGOS SUPERFLUOS}

En el periódico madrileño El Sol publicó Ortega una miscelánea de artículos a lo largo de varios años, muchos de los cuales no habían sido recogidos en algunas ediciones de sus Obras completas. Entre ellos se encontraba el ensayo que tituló «Diálogos superfluos» (junio de 1918), en los que dos personajes imaginarios llamados Juan Esturión y Juan Rémora simbolizaban dos caracteres a los que ya Cervantes había definido en dos pasajes. Decía el autor del Quijote que el esturión es un pez obstinado en bogar siempre contra la corriente, mientras que el pez rémora, aun siendo pequeño, se adhería al flanco de una nave y le impedía o, al menos, le dificultaba el rápido avance en su navegación. Esa rémora, en un sentido más amplio, es lo que los romanos denominaban «broma», si bien lo que impedía una fácil navegación no eran los peces, sino la cantidad de sustancias que se iban adhiriendo al casco del barco, con el resultado de acumular un peso extra que provocaba una navegación más lenta; de ahí la necesidad de sacar a tierra las naves con el fin de limpiar

${ }^{13}$ OC. I, 530; en "1912: Una visita a Zuloaga». 2004. Taurus.

${ }^{14}$ OC. II, 288; en «El Espectador [1916-1934]. II: "La vida en torno. Muerte y resurrección”». 2004. Taurus. 
los fondos y lograr un más suave deslizamiento y una mayor rapidez. Juan Esturión propondrá a Juan Rémora un acuerdo sobre la "nave del Estado», para que, sin defender al Gobierno de entonces, se reflexionara sobre la situación de España y no se hiciera de aquel gabinete ministerial un nuevo invento para no trabajar. Ante la irritación de Juan Rémora como buen celtíbero, Juan Esturión le responde recordándole que la conversación es el más fino obsequio de los dioses al hombre y que dialogar es sentirse dos y palpar con nuestro perfil el perfil del alma ajena. Recuerda que, en España, el hombre que era de otra opinión, el hetero-doxo, solía ser llevado a la hoguera, o cuando menos, corrido por las calles como un can sarnoso. Tal método no ha traído los mejores resultados y por ello propone buscar hombres que no piensen como uno piensa, porque cree que existe en el hombre una especie de instinto de transmigración, un anhelo de más allá del propio individuo. Per troppo variare natura è bella, cantaba Giordano Bruno. Y concluye con las siguientes intervenciones de sus dos personajes:

Juan Esturión.- [...] Amemos lo diferente y aun lo adverso, amigo Rémora: conversemos tranquilamente cultivando un sabroso desacuerdo.

Juan Rémora.- ¡Tiene usted razón, tiene usted razón! ¡Hay que conversar! San Juan dice en su Evangelio que «en el comienzo era el Verbo, el Logos», que quiere decir: en el comienzo era la conversación.

Juan Esturión.- Lo cual es un pequeño error de San Juan. Porque la conversación resulta imposible sin la cortesía. Corrijamos, pues, el versículo y digamos: «En el comienzo era la cortesía... y luego empezó la conversación».

Juan Rémora.- Bueno, pero decía usted que este Gobierno, el mejor posible, no es un buen Gobierno...

Juan Esturión.- Eso decía, y mañana -ahora es tarde- aspiraré a convencerle a usted de ello. ${ }^{15}$

\subsection{Real Orden Sobre la PRENSA del SeÑor Dato Y POSIBLE IMAGEN APOCALÍPTICA}

Un artículo titulado «El señor Dato, responsable de un atropello a la Constitución» fue la reacción que José Ortega y Gasset tuvo nada más leer una Real Orden que restringía su capacidad de publicación de prensa escrita. Argumentaba el filósofo madrileño que ni el señor Dato ni Aznar ni ningún otro tenían capacidad para impedir la libertad de expresión ni tampoco de intervenir en la industria y comercio de los periódicos. El enfado de Ortega era tal que se atrevió a escribir de sí mismo

15 OC. III, 2005; pp. 105-107; publicado por primera vez en el periódico El Sol, 26 de junio de 1918. 
para manifestar su rotundo rechazo a la decisión de Eduardo Dato ${ }^{16}$, presidente del gobierno en 1920. Dice así el filósofo madrileño:

Aunque soy muy poco periodista, nací sobre una rotativa. Tal vez por este género de natividad me he sentido impulsado a desplazar algún esfuerzo hacia esta forma de labor literaria. Hace bastantes años fundé con el señor Rengifo una revista semanal: Faro; luego la revista España; más tarde colaboré en la fundación de El Sol. Con alguna hipérbole, pero dentro del sentido literal que el vocablo posee, puedo, en consecuencia, aspirar a que el añalejo me conmemore bajo el título de fundador. Resuelto por otra parte a no ser mártir, pienso en que mañana me ocurra fundar alguna otra publicación. Y, entonces, súbitamente, me sobrecoge una revelación, una imagen apocalíptica, pero no trágica como la de San Juan, sino bufonesca como las de Muñoz Seca ${ }^{17}$. Resulta que «mi» libertad industrial e intelectual ha sido enajenada ya por esa docena y media de señores reunidos en La Época. Si no se ha contado con los periódicos de hoy, era gollería pedir que se contase con los de mañana. La consecuencia es que, por ejemplo, el señor Luca de Tena ${ }^{18}$ ha enajenado «su» libertad industrial y, de paso, la «mía». Esta imagen, la imagen del señor Luca de Tena

${ }^{16}$ Eduardo Dato e Iradier (La Coruña, 12-08-1856 - Madrid, 08-03-1921), abogado y político español, varias veces ministro y presidente del Consejo de Ministros durante el período de la Restauración, pertenecía al Partido Conservador, fue ministro de Gobernación, Gracia y Justicia, Estado y Marina, y presidente del Consejo de Ministros en tres ocasiones. En 1914 decretó la neutralidad de España cuando estalló la Primera Guerra Mundial. Más adelante se enfrentó a la violencia ocasionada por los conflictos laborales y aplicó una política represiva contra el movimiento anarcosindicalista. Fue también alcalde de Madrid, presidente del Congreso de los Diputados y diputado varias veces por los distritos de Murias de Paredes y Vitoria. En 1921 fue asesinado en un atentado.

${ }_{17}$ Pedro Muñoz Seca (Puerto de Santa María, Cádiz, 20-02-1879 - Paracuellos del Jarama, Madrid, 28-11-1936), escritor y dramaturgo perteneciente a la Generación del 14 o Novecentismo. Estudió bachillerato en el colegio jesuita «San Luis Gonzaga» de El Puerto de Santa María (Cádiz) junto a Juan Ramón Jiménez y Fernando Villalón. En 1901 terminó Filosofía y Letras y Derecho en Sevilla. En Madrid en 1904 estrenó El contrabando en el Teatro Lara, y trabajó de profesor de griego, latín y hebreo. En 1908 comenzó a trabajar en el Ministerio de Fomento y se casó con la cubana María de la Asunción de Ariza y Díez de Bulnes. Entre los años 1910 y 1920 se consolidó como autor teatral y creó el género denominado "astracanada». Su obra más célebre dentro de este género fue La venganza de Don Mendo (1918). De 1931 en adelante centra sus sátiras contra la República; estrena La oca, caricatura del comunismo y del igualitarismo. Cuando se inició la Guerra Civil fue detenido y fusilado por ser católico en Paracuellos del Jarama.

${ }^{18}$ Torcuato Luca de Tena y Álvarez Ossorio (Sevilla 21-02-1861 - Madrid 15-04-1929) escritor, periodista, empresario y político. Fundador del semanario Blanco y Negro (10-05-1891), se unió al grupo Prensa Española, del que también formó parte el periódico ABC (como semanario desde 01-01-1903, como diario desde 01-06-1905), entre otras empresas periodísticas. Fue agregado diplomático en la embajada de España en Marruecos (1876-1878). Terminada su licenciatura en la Universidad madrileña, estuvo diez años dedicado a los negocios familiares y a la alta banca; viajó con frecuencia por el extranjero, donde pudo estudiar de cerca el grado de adelanto que tenía a la sazón el periodismo europeo. Militó en el partido liberal conservador y fue diputado en varias legislaturas. Rehusó dos veces ser ministro. Alfonso XIII le otorgó el título de marqués de Luca de Tena. 
enajenando mis libertades junto con las suyas, me produce tan saludable hilaridad que en cierto modo contrarresta la indignación provocada en mi fuero íntimo por la Real Orden. Como los periódicos son, a lo mejor, dirigidos por el menos capaz, puede ocurrir que un fabricante de cosméticos haya enajenado mi futura libertad de publicar. ${ }^{19}$

\subsection{EL LÓGOS SE HIZO CARNE}

Uno de los ensayos más leídos de Ortega es el titulado «Ética de los griegos», que es un comentario escrito a partir de la lectura que hizo del libro de Ernst Howald, Ethik des Altertums ${ }^{20}$, y que fue incluido en el libro Espiritu de la letra, publicado en 1927, en el que se recogían doce ensayos, entre los cuales se encontraban también los titulados «Orígenes del español» y «Oknos el soguero». En una de sus expresiones favoritas Ortega dirá que de la «Ética de los griegos» habría que decir que todo lo dicho hasta ese momento debería dejar de decirse, porque Grecia es una piedra de toque para el intelectual. Durante los siglos transcurridos desde la aparición de Grecia en Occidente, la cultura europea ha buscado su ideal y éste ha sido hasta ahora la cultura griega; lo más entrañable y eficiente de una cultura, la fuerza que en ella plasma y dirige todo lo demás es el repertorio de anhelos, de normas, de desiderata... su ideal. El libro de E. Howald, profesor de Filología Griega en Zurich, describe la ética de los antiguos griegos, después de haber definido su realidad. Tras un largo recorrido por las ideas expuestas por el profesor suizo, Ortega sintetiza la cuestión de la ética griega antigua frente al hombre actual, dado que para nosotros conocer es buscar ideas que se ajusten a la realidad y la transcriban, mientras que para Parménides, Platón y Aristóteles conocer es descubrir que la realidad única es la idea, lo pensado, de tal forma que el griego no investiga las cosas, sino las ideas; es un camino que se dirige en dirección contraria a la que el hombre occidental sigue en nuestros días. Hasta el mismo Aristóteles sigue el esquema griego antiguo, porque para el estagirita la realidad máxima es la sustancia, que es, a su vez, una idea y, como tal, puede hacer que se plasme en materia y se encarne. De ahí que el mismo Ortega acuda al evangelista San Juan para resumirlo en las conocidas palabras de:

Cuando el cristianismo sostiene en el Evangelio de San Juan que el verbo, el Lógos, se hace carne, resume toda la Grecia clásica. ${ }^{21}$

${ }^{19}$ OC. III, 345; El Sol, 17 de junio de 1920.

${ }^{20}$ Literalmente traduciríamos Ética de la Antigüedad. Munich y Berlín, Oldenbourg, 1926.

${ }^{21}$ OC. IV, 141. Taurus 2005. [«Ética de los griegos», 1926]. 


\subsection{El CALIFICATIVO de SAN JUAN}

Hemos visto ya en dos pasajes anteriores que Ortega califica al evangelista San Juan con el apelativo de "el viejo virgen $»^{22}$, dado que parece que mantuvo su virginidad a lo largo de toda su vida. Ortega recuerda en una tercera ocasión esta circunstancia del cuarto apóstol, cuando escribió a modo de notas unos apuntes que han sido recogidos en el volumen séptimo de la última edición de sus Obras completas (Madrid 2004-2010) y que encabeza el título en alemán Stumpfheit ${ }^{23}$. No se trata de una narración escrita, sino simplemente de una especie de cuaderno de notas, en el que han sido incluidos hasta setenta apuntes de desigual extensión, seguramente como recordatorios para próximos ensayos, comentarios o conferencias. Estas notas seguramente correspondan a distintas épocas de su vida. En esta ocasión el texto aparece ordenado con el número dieciséis, dentro de las citadas setenta anotaciones, en el que lo más destacado para Ortega de la persona conocida por Juan el Evangelista es el hecho de haber permanecido virgen durante toda su larga vida. El texto de Ortega dice así:

Para mí la palabra más representativa que puede decirse de San Juan Evangelista es el «viejo virgen». La Apocalipsis se explica por esa tremenda tristeza fisiológica del inmaculado que le desparrama místicamente por sobre la naturaleza. ${ }^{24}$

\subsection{El LógOS de Filón, Plotino y SAN JuAN}

En 1929 dictó Ortega y Gasset diez lecciones que constituirían posteriormente su libro ¿Qué es filosofía? ${ }^{25}$ Ortega va a hablar en estas lecciones de las cosas que hay en la naturaleza, las conozcamos o no, de las que erróneamente creamos que hay, pero, en verdad, no las hay; y de aquéllas otras que estamos seguros de que sí las hay. Ortega hablará de la paradoja, como el hecho de que desde Descartes el mundo camina al revés, incluyendo en el registro de apuntados al cartesianismo a Leibniz, Kant, Fichte y Hegel, entre otros, pues han convertido la filosofía en una doctrina antinatural que no se puede entender sin una previa iniciación: como si el pensamiento se hubiera tragado el mundo, dado que las cosas se han convertido en meras ideas: son el reflejo de una filosofía idealista. La superioridad de ese

${ }^{22}$ Véanse las referencias en 3.2 y 3.3.

${ }^{23}$ Este término alemán es polisémico y lo entendemos como 'apatía', 'letargo', 'embotamiento'; en esta ocasión, con el campo semántico del 'letargo', lo podríamos traducir por 'en reserva', apuntes para un posterior desarrollo, pues son unas notas que se guardan para poder ampliarlas posteriormente.

${ }^{24}$ OC. VII, 159. Madrid 2007. El escrito (borrador) está fechado en marzo de 1909.

${ }^{25}$ Véase OC. VIII, 235-374, Madrid 2008, Taurus. Nos interesa especialmente la lección VI, impartida el viernes 03-05-1929. 
idealismo se debe a que ha descubierto una cosa cuyo modo de ser es radicalmente distinto del que poseen las otras cosas. Y es que este idealismo consiste en un ser para sí mismo, en un darse cuenta de sí mismo. El cuerpo es gravedad, peso, pero no es pesarse a sí mismo. [...] Por tanto, algo está haciendo mal el hombre contemporáneo cuando no distingue el ser del hacerse. No se trata de entender el ser como algo que es para sí mismo, o en saberse a sí mismo, sino en «ser para otro». [...] Y es que el mundo antiguo en su totalidad sólo conoce un modo de ser que consiste en exteriorizarse, por tanto, en abrirse u ostentarse, en ser hacia afuera. De aquí el hecho de que llamasen al hallazgo del ser, esto es, a la verdad, «descubrimiento», $\dot{\alpha} \lambda \hat{\theta} \theta \varepsilon \iota \alpha$, manifestación, desnudamiento. Y en ese contexto dice Ortega:

Tampoco la idea platónica consiste en darse cuenta de sí misma: la idea de lo bueno o de lo igual no sabe qué es bondad o igualdad. Tampoco la forma aristotélica consiste en ese saberse y tampoco el dios de Aristóteles a pesar de su definición -como espero veamos-, ni tampoco el Lógos de Filón y Plotino y San Juan Evangelista, ni tampoco el alma de Santo Tomás de Aquino. Se trata, en efecto, de una noción, de la noción más peculiar de la modernidad. ${ }^{26}$

\subsection{LA DIVINIZACIÓN DE LA INTELIGENCIA Y EL EVANGELIO DE SAN JUAN}

Ortega y Gasset impartió dos veces un curso titulado "La razón histórica»: la primera en 1940 en Buenos Aires y la segunda en 1944 en Lisboa. Lógicamente el texto de cada conferencia era distinto, pues no sólo el auditorio era diferente, sino que las circunstancias de cada auditorio eran también diferentes. En efecto, aquellos años de guerra civil recién acabada en España y los siguientes años de segunda guerra mundial que entonces se estaban viviendo no eran ajenos a las circunstancias de Ortega y de la intelectualidad española. Sí coincidía el inicio de ambos ciclos de lecciones en el hecho de que la tarea anunciada era muy difícil de explicar, pues era una propuesta innovadora del propio Ortega, con la que aspiraba a dar una nueva visión de la filosofía partiendo de sus orígenes griegos.

Para encontrar la referencia al apóstol evangelista hay que saltar a la quinta lección del segundo ciclo de conferencias impartido en 1944. En sus primeras líneas habla Ortega de que hay una diferencia radical entre el beneficio material de las ciencias naturales y el cultivo de la filosofía, pues ésta parece una consustancial inutilidad, a pesar de lo cual el saber filosófico es considerado como el único, auténtico y máximo saber, y concluirá Ortega esta introducción recordando que todas las ciencias

${ }^{26}$ OC. VIII, 315. 2008. «¿Qué es filosofía?». Madrid, abril-mayo 1929; [= viernes, 3 de abril de 1929]). 
son más necesarias ( $\alpha v \alpha \gamma \kappa \alpha \iota o ́ \tau \varepsilon \rho \alpha \imath \pi \alpha ́ \sigma \alpha \imath$ ), entendidas como más útiles, pero ningu-

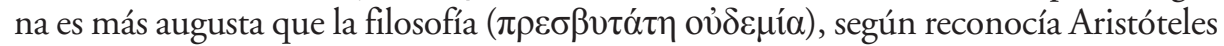
en su Metafisica. A esta afirmación Ortega añadía el problema que ese reconocimiento implicaba cuando afirmaba:

Con esto aludo a la enorme cuestión de que los griegos, descubridores de la inteligencia o razón y con ello de la teoría, sintieron tal entusiasmo por su ejercicio, que lo consideraban como el valor supremo en la realidad universal. Como tal valor supremo exige que todo lo demás se justifique ante él, pero él mismo no necesita justificación, o se justifica a sí mismo sin más que ser y actuar. Esta apoteosis -en el sentido estricto de la palabra-, por tanto, esta beatificación o divinización de la inteligencia -o lógos-y de la teoría, por los griegos, que entre sus múltiples efectos tuvo el de ocasionar que el evangelio de San Juan comience diciendo: «En el principio era

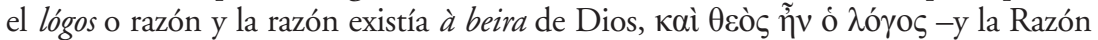
misma era Dios-», esta apoteosis de la inteligencia, digo, heredada con el resto del tesoro helénico por la cultura europea -Santo Tomás contribuyó sobremanera a ello- es lo que llamamos «intelectualismo». Porque se olvida demasiado que el cristianismo occidental, como en la última lección insinué, aunque no estoy seguro de que se reparó bien en ello, cuando de pasada aludí a San Anselmo, figura que inicia y resume toda la evolución posterior de la llamada "civilización cristiana", el cristianismo europeo ha sido, bajo su caparazón de dogmas revelados, intelectualista y a potiori racionalista. Basta recordar que el hombre, no diré más genial, pero sí más normal representante del catolicismo en los últimos cuatro siglos, el gran Bossuet, decía que Dios mismo «tenía que tener razón». ${ }^{27}$

\section{LOS OTROS TRES EVANGELISTAS}

Dado el interés, aparentemente anecdótico, de las referencias orteguianas a los cuatro evangelistas, recogemos en los siguientes párrafos las alusiones de Ortega y Gasset a los otros tres evangelistas, los llamados Sinópticos: San Mateo, San Marcos y San Lucas.

\subsection{Las RefEREnCias al Evangelio de SAN MATEO ${ }^{28}$}

4.1.a. El primer comentario de Ortega y Gasset en el que alude al primer apóstol evangelista sinóptico, San Mateo, está relacionado con un estudio de

${ }^{27}$ OC. IX, 685-686; 2009: «La Razón Histórica» [curso de 1944] Lección V.

${ }^{28}$ El apóstol y evangelista San Mateo (Mateo significa «don del Señor») es representado acompañado de un hombre o de un ángel, porque su evangelio empieza con la genealogía de Jesucristo, el hijo del Hombre. Mateo nació en Nazaret (Israel) y se acepta el año 74 d.C como el de su muerte. Se dice que sus restos están enterrados en la Catedral de Salerno (Italia). Parece que su nombre original 
Rodolfo Bultmann ${ }^{29}$, publicado bajo el título La investigación de los Evangelios Sinóp$t_{i c s^{30}}$, un folleto de treinta y seis páginas, en el que se resumía el estado actual (referido al año 1925) de la exégesis evangélica.

Ortega destacará el hecho de que en España se desatendía la historia del cristianismo, de lo cual no era culpable la Iglesia Católica, y estaba seguro de que el catolicismo no se opondría a que hubiera una búsqueda de claridad científica sobre el origen de su doctrina y de su organización. Varios comentarios más acerca de los aciertos y errores en la práctica de los católicos llevaron a Ortega a recomendar que los católicos (españoles) sintieran el orgullo de su catolicismo e hicieran de él lo que se hizo en otros tiempos: un instrumento exquisito, «rico de todas las gracias y destrezas actuales, apto para poner a España en forma ante la vida presente».

Esta inicial reflexión llevó a Ortega a concluir que surgieron tres modelos de Iglesia: primero, el modelo de los que vivieron en torno a Jesús, que constituyeron una primitiva comunidad judeocristiana alrededor de Santiago, el hermano del Señor, y de la Piedra apostólica [Pedro], la llamada comunidad de Jerusalén; segundo, el modelo de cristianismo surgido entre los gentiles y alentado por San Pablo, la llamada Iglesia de los gentiles, que se nutría de una atmósfera helenística. La suma de estas dos corrientes dio como resultado los Evangelios. En tercer lugar, la investigación posterior ha llevado a descubrir una tercera zona de influencia en el cristianismo primitivo, la procedente de Irán y Babilonia, que ve en los esenios y en San Juan Bautista una fermentación religiosa emanada de Persia y Babel.

hebreo era Leví (hijo de) Alfeo. Vivía en Cafarnaúm, ciudad comercial situada en la ruta de las caravanas entre Siria y Egipto. Mateo era recaudador de impuestos y un día, cuando se hallaba en su despacho, junto al mar de Galilea, Jesús le dijo: «Sígueme». San Mateo respondió con admirable prontitud a la exhortación al apostolado del Maestro, se despidió con un suntuoso banquete de sus amigos y de su vida pasada y siguió, pobre, los pasos y doctrina de Jesús de Nazaret. La tradición recoge que evangelizó Judea y fue misionero en Etiopía y Persia. Vivió y escribió su Evangelio en Antioquía. Véase Antonio Piñero: Todos los Evangelios. Madrid 2009. Editorial Edaf; y Guía para entender el Nuevo Testamento. Madrid 2006. Editorial Trotta.

${ }^{29}$ Rudolf Karl Bultmann (Wiefelstede, 20/08/1884 - Marburgo 30/07/1976) fue un teólogo protestante alemán, autor de varios libros, en los que se ocupó del «Jesús histórico», sobre el que se declaró escéptico, al no poder acceder a él, y optó por un «Cristo de la fe».

${ }^{30}$ Die Erforschung der synoptischen Evangelien. [La investigación de los Evangelios sinópticos] (Giessem, edición de Alfred Töpelmann, 1925, 36 p.). Una segunda edición de Die Erforschung der synoptischen Evangelien apareció en 1931, cuando Bultmann había experimentado ya una conversión personal e intelectual. Se trata de un ensayo exegético en la línea de la Formgeschichte de K. L. Schmidt y M. Dibelius, que fijaba su atención en la exégesis correcta del texto bíblico a través de los estilos literarios. Colaboró con K. Barth y F. Gogarten en la revista Zwischen den Zeiten, órgano de la teología dialéctica. Tras su encuentro con M. Heidegger, Bultmann se separó de Barth, para dedicarse a su nuevo programa de «desmitificación» del cristianismo. Entre sus obras cabe citar las siguientes: Jesús (1926), Teología del Nuevo Testamento (1948-1953), Creer y comprender (1933-1965, 4 vols.), El Evangelio de Juan (1941). 
Ortega dedicará unas palabras de elogio a Eduardo Meyer, quien en sus tres tomos de Origen y comienzos del cristianismo (1921-1923) ${ }^{31}$ había expuesto con rigor el valor documental de Hechos y de Epistolas, hasta el punto de considerar que muchas informaciones relativas a la historia antigua no resistirían un juicio crítico tan exhaustivo como el que se exigía en la valoración de los escritos neotestamentarios.

Por otro lado, Ortega añadirá la importancia esencial para la tradición cristiana que tuvo el descubrimiento arqueológico que se produjo en 1911 en Delfos. En efecto, se encontró una piedra con una inscripción, en la que se decía que el Emperador Claudio se dirigía a su amigo Junio Gallio como procónsul en Acaia; era el año 52 d.C., y coincide esa fecha con la noticia recogida en Hechos (XVIII, 12-17) que habla de la acusación de los judíos de Corinto contra San Pablo ante el procónsul Gallio. Tras estos antecedentes, Ortega añade:

Esta disensión no impide que exista gran acuerdo sobre temas de la mayor importancia, como es el orden de precedencia de los Evangelios. Hoy es general la opinión de que San Mateo y San Lucas proceden de San Marcos, si bien ambos usan, además, otra fuente perdida para nosotros, compuesta de «dichos» $\mathrm{y}$ «sentencias» de Jesús. Colecciones de este género debió de haber muchas antes de los Evangelios. La predicación obligaba a formar estas antologías de frases divinas, de narraciones de milagros, de escenas ejemplares espumadas de la vida del Señor. El trabajo que hoy ocupa a los historiadores del Evangelio se desprende claramente de esta situación. Retrotraídos los demás sinópticos al libro de San Marcos, y reconociendo en éste una redacción de conjunto hecha sobre las primeras colecciones de «dichos» $\mathrm{y}$ "hechos», la cuestión está en separar la «redacción» de lo «redactado» ${ }^{32}$. De esta manera puede llegarse a reconstruir esa serie de estrictas palabras y acciones de Jesús, libres por completo de la "forma» que el escritor evangélico -al fin y al cabo "escritor»les ha dado. Los Evangelios, como las Epístolas y los libros «Hechos Apostólicos», fueron en aquella fecunda época géneros literarios, que, como tales, tenían una "forma", una estructura predeterminada, dentro de la cual, la materia de la historia de Jesús, de su vida y doctrina, era plasmada. Lo importante para nosotros, para el cristiano como para el historiador del cristianismo, es esta materia. Si estudiamos las leyes que regían aquellas «formas» de redacción, aquellos «géneros» literarios, podemos restarlas del producto y aislar en su pureza la materia viva, eléctrica, conmovedora, de los «hechos» $\mathrm{y}$ «dichos» de Jesús. Este método, que se ha llamado «histórico formal o de las formas", es acaso el rasgo distintivo de la filología actual frente a los usados por la generación anterior. Todas las literaturas van siendo sometidas a él, y es evidente la fertilidad de sus resultados. ${ }^{33}$

${ }^{31}$ Eduard Meyer (Hamburgo 1885 - Berlín 1930), historiador alemán, estudió en las universidades de Bonn y Leipzig. Fue profesor en Breslavia en 1885, Halle en 1889, y Berlín en 1902. Pronunció una conferencia en la Universidad de Harvard en 1909. Su obra historiográfica, Geshichte des Altertums, en cinco volúmenes, se detiene en la época de Filipo II de Macedonia.

${ }^{32}$ Entiéndase «distinguir lo que se redacta ahora a partir de lo que se recibe ya redactado».

${ }^{33}$ OC. Iv, 128-129. 2005. «La forma como método histórico», 1927, en el libro Espíritu de la letra. 
4.1.b. Un segundo comentario de Ortega sobre el evangelista San Mateo aparece en el libro titulado En torno a Galileo, publicado en 1947, aunque su contenido procede de unas lecciones impartidas con ocasión de un curso dado en 1933, en la cátedra Valdecilla de la Universidad Central de Madrid. En efecto, las lecciones V-VIII fueron publicadas en 1942 como un libro aparte y bajo el título «Esquema de la crisis», al que precedía una nota aclaratoria en la que el autor informaba que esas cuatro lecciones respondían a la necesidad de explicar la situación vital de las generaciones que transcurrieron entre los años 1550 a 1650, época en la que se instauró el pensamiento moderno. Pues bien, en la lección IV de ese libro hay una referencia a San Mateo, cuando Ortega habla del método de las generaciones en la historia y explica:

Digo, pues, que se ha confundido hasta ahora, más o menos, la idea de las generaciones con la genealogía, con la serie biológica -podía mejor decirse zoológica-, de hijos, padres, abuelos. Todas las historias primitivas, por ejemplo, las hebreas, están construidas al hilo de las genealogías. Asi empieza el Evangelio de San Mateo: "Libro de la generación de Jesucristo, hijo de David, hijo de Abraham. Abraham engendró a Isaac. E Isaac engendró a Jacob. Y Jacob engendró a Judas y sus hermanos, etcétera, etcétera». De esta manera el historiador primitivo coloca a Jesús en la altura determinada del destino general humano que miden las generaciones genealógicas. Esto revela una aguda intuición de que la vida de un hombre está encajada en un proceso más amplio, dentro del cual representa un estadio. El individuo está adscrito a su generación, pero la generación está, no en cualquiera parte -utópica y ucrónicamente-, sino entre dos generaciones determinadas. Lo mismo que en nuestra vida individual el acto que ejecutamos ahora, por tanto, lo que ahora somos, asume un trozo irreparable del tiempo definido que va a durar nuestra existencia, así cada generación representa un trozo esencial, intransferible e irreparable del tiempo histórico, de la trayectoria vital de la humanidad. Por eso es el hombre sustancialmente histórico: por eso decía yo a ustedes en la primera lección que la vida es lo contrario del utopismo y el ucronismo -es tener que estar en un cierto aquí y en un insustituible y único ahora. ${ }^{34}$

4.1.c. «Reunidos en mi nombre, yo estaré con vosotros».

Un tercer pasaje de Ortega recuerda de nuevo a San Mateo, cuando el filósofo madrileño escribe su ensayo Epílogo de la Filosofia, publicado en 1943, en Buenos Aires, donde compartía algunas lecciones con Julián Marías. Éste había impartido unas lecciones de historia de la filosofía con precisión y sobriedad y ahora le tocaba a Ortega expresar el epílogo de esa historia filosófica. Ortega distribuyó su exposición en cuatro lecciones, siendo la cuarta titulada «La mismidad de la filosofía». Se centrará en la idea de que lo que más y mejor se conserva de lo pasado son

${ }^{34}$ OC. VI, 399-400. En «Lección IV: el método de las generaciones en historia». 
los nombres, que son la forma de la relación distante entre nuestra mente y las cosas, pues los nombres son la primera y muchas veces la única comunicación que nos llega. Y en este pasaje explicará que el nombre es sólo la referencia a una cosa, está por ella, en lugar de ella, y por eso es símbolo, como cuando una cosa se presenta como representante de otra cosa que no está presente: es una relación simbólica. En esta explicación se explica la cita de San Mateo, cuando Ortega escribe:

Aparecen súbitamente ante nosotros, se deslizan en nuestro oído cuando aún las cosas que ellos denominan se hallan remotísimas de nosotros -tal vez para siempre, invisibles y allende el horizonte. Son, pues, los nombres como esos pájaros que en alta mar vuelan de pronto hacia el navegante y le anuncian islas. La palabra, en efecto, es anuncio y promesa de cosa, es ya un poco la cosa. Hay mucha menos extravagancia de lo que parece en la teoría de los esquimales, según la cual el hombre es un compuesto de tres elementos: el cuerpo, el alma y... el nombre. Lo mismo pensaban los arcaicos egipcios. Y no se olvide aquello de: «Donde dos o tres se junten en mi nombre, yo estaré en medio de ellos». (San Mateo 18, 20). ${ }^{35}$

\section{1.d. Sobre un cuadro de Tintoretto.}

En un curso de cuatro lecciones sobre pintura impartido en 1947 Ortega dedicó un comentario a Tintoretto, cuando explicaba el paso de una pintura que quería representar lo que las cosas debían ser a representar lo que las cosas eran, esto es, lo que se pintaba en torno al año 1540 (La Madonna) a lo pintado en 1618 (El Aguador). Se fija Ortega en la pintura veneciana de Jacopo Robusti «Tintoretto» (1518-1594) y comentará el manierismo o estilismo que adquirió el arte pictórico en el siglo XVI, cuando este pintor, por ejemplo, además de complacerse en lo visible y en lo externo de los cuerpos, logró que esa representación corpórea expresase estados del alma, como el arrebato místico, y si hubiera un milagro, las almas quedarían conmocionadas por lo maravilloso. Mas al describir uno de los cuadros de Tintoretto que expresa ese éxtasis fugaz y extraordinario, Ortega alude al cuadro denominado en este ensayo El Milagro de San Mateo, obra de Tintoretto. Frente a la suavidad y tranquila ondulación de las formas que se hallan en la Madonna, las figuras que aparecen ahora en ese cuadro del Milagro están agolpadas, agitadas, con movimiento frenético. A lo que Ortega añade:

La estilización aquí, como en Miguel Ángel, sólo que aquí exagerada, consiste en el formalismo del puro movimiento. En cierto modo, quien se agita, vibra, se mueve y retiembla en todo el cuadro, compuesto de acusados dinamismos que acentúa,

${ }^{35}$ OC. Ix, 614-615. Ortega añade una nota al pie de página para recordar que en el capítulo «Lógica y ontología mágicas», habla de que «el hombre vio el pensar = logos = palabra, como viniendo del ser y residiendo en él». 
como el acento sobre una palabra impresa, esa figura de San Mateo, que raudo, como un buitre o un gerifalte, con vuelo de avión que va a aterrizar, penetra por lo alto en el cuadro, en oblicua diagonal, es decir, yendo hacia el fondo imaginario de él. ${ }^{36}$

\subsection{Referencias al Evangelio de SAn MarCos ${ }^{37}$}

\section{2.a. El ocaso de las revoluciones.}

Ortega escribió varios apéndices a su libro El tema de nuestro tiempo (1923), entre los cuales se encuentra el titulado «El ocaso de las revoluciones», que es un largo ensayo en el que desarrolla su teoría de las revoluciones, cuando afirma que «en todo gran ciclo histórico llega un momento en el que se dispara el mecanismo revolucionario irremisiblemente ${ }^{38} \mathrm{y}$ es la vida la que entonces se pone al servicio de las ideas. Pues bien, este ensayo está precedido de un versículo del Nuevo Testamento, atribuido al evangelista San Marcos que dice: «El sábado por causa del hombre es hecho, no el hombre por causa del sábado», frase que será repetida más adelante en el cuerpo del ensayo, cuando hable de los sucesivos fracasos y de las nuevas reacciones que se repetirán mientras el hombre no se dé cuenta de que el fracaso o el mal éxito no es debido a las intrigas enemigas, sino a la contradicción misma del propósito. Y lo explica en las siguientes líneas:

Las ideas políticas pierden brillo y fuerza atractiva. Se empieza a advertir todo lo que en ellas hay de fácil y pueril esquematismo. El programa utópico revela su interno formalismo, su pobreza, su sequedad, en comparación con el raudal jugoso y espléndido de la vida. La era revolucionaria concluye sencillamente, sin frases, sin gestos, reabsorbida por una sensibilidad nueva. A la política de ideas sucede una política de cosas y de hombres. Se acaba por descubrir que no es la vida para la idea, sino la idea, la institución, la norma para la vida, o, como dice el Evangelio, que «el sábado por causa del hombre es hecho, no el hombre por causa del sábado». ${ }^{39}$

4.2.b. Comentado ya el pasaje que recoge la precedencia de los Gnósticos (4.1.a.), pasamos al pasaje de Ortega, en el que recuerda en nota a pie de página una cita del evangelista San Marcos. El pasaje pertenece a la conferencia que Ortega pronunció en Berlín, en 1949, bajo el título De Europa meditatio quaedam. Había

${ }^{36}$ OC. IX, 917; «Curso de cuatro lecciones. Introducción a Velázquez. Lección III». Nos ha quedado la duda del nombre del cuadro: Ortega lo denomina «El Milagro de San Mateo», mientras que otras fuentes lo denominan «El Milagro de San Marcos».

${ }^{37}$ El león se identifica con Marcos, porque su Evangelio comienza hablando de Juan el Bautista, «Voz que clama en el desierto». Dicha voz sería como la del león.

${ }^{38}$ OC. III, 619-638, especialmente 626.

${ }^{39}$ La cita corresponde al Evangelio de San Marcos, 2.27. Véase Nueva Biblia Española, edic. c., Madrid 1977. 
finalizado la Segunda Guerra Mundial, la ruina de Europa por la guerra era común con la ruina española por su Guerra Civil y por su negativa economía; una dictadura se había instalado en España, donde a Ortega no se le facilitaba el contacto con los jóvenes universitarios, salvo esporádicos cursillos o alguna conferencia, por lo que el hecho de ser invitado a dar una conferencia en Berlín fue una ocasión de volver a hablar a la juventud y a sus colegas alemanes. El tema era el futuro de Europa; de él Ortega había hablado desde sus primeros artículos, en los que proponía una unión de naciones europeas que permitiera convivir con las grandes naciones que habían surgido tras las dos guerras mundiales: la Unión Soviética y los Estados Unidos de América, además de China y Japón. La perspectiva de Ortega, imposible de sintetizar en unas líneas, apuntaba al hecho de que para Europa ya era tarde y sólo cabía la superación del nivel de naciones, porque éstas como forma perfecta de vida colectiva era ya un anacronismo: las naciones europeas carecían ya de fertilidad hacia el futuro y sólo las podría salvar una unidad política supranacional, pues de lo contrario, acabarían viviendo envilecidas. A lo que añadía Ortega:

Desde 1850, por un mecanismo inexorable adscrito a la democracia, (aunque, en verdad, no le es congénito), la fauna de los políticos europeos ha ido degenerando sin pausa, generación tras generación, como se podría demostrar ex abundantia con gran facilidad. Cada día fueron menos auténticos gobernantes, es decir, dirigentes responsables y previsores de los pueblos. Fueron progresivamente dirigidos por las masas hasta convertirse estos últimos años en simples exponentes de sus momentáneos apetitos. Refiriéndome al enorme y craso error, oriundo lisa y llanamente de la más elemental ignorancia en quienes lo cometieron, que fue la creación, tras la primera guerra mundial, de la soi-disant «Sociedad de Naciones», escribía yo en 1937: «El "espíritu" que impulsó hacia aquella creación, el sistema de ideas filosóficas, históricas, sociológicas y jurídicas de que emanaron su proyecto y su figura estaba ya históricamente muerto en aquella fecha, pertenecía al pasado, y lejos de anticipar el futuro era ya arcaico. Y no se diga que es cosa fácil proclamarlo esto ahora. Hubo hombres en Europa que ya entonces denunciaron su inevitable fracaso. Una vez más aconteció lo que es casi normal en la historia, a saber, que fue predicha. Pero una vez más también los políticos no hicieron caso de esos hombres. ${ }^{40}$

\section{ta San Marcos:}

${ }^{40}$ Ortega incluye en nota al pie de página la siguiente conclusión recordando al evangelis-

«Hasta el punto de que da ganas de denominarlos con la estupenda expresión de desprecio que emplea

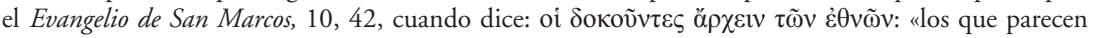
mandar en los pueblos». Véase Luis Alonso Schökel - Juan Mateos: Nueva Biblia Española. Madrid 1977. Ediciones Cristiandad; p.1573.

El pasaje de Marcos 10, 42 dice:

Jesús los reunió y les dijo: «Sabéis que los que figuran como jefes de los pueblos los tiranizan, y que los grandes los oprimen, pero no ha de ser así entre vosotros; al contrario, el que quiera subir, sea servidor vuestro, y el que quiera ser el primero, sea esclavo de todos, porque tampoco este Hombre ha venido para que le sirvan, sino para servir y para dar su vida en rescate por todos». Ídem pp. 1574-1575. 


\subsection{Referencias al EVangelista San LuCaS ${ }^{41}$}

4.3.1. Hemos citado en epígrafes anteriores varios pasajes en los que se nombra a San Lucas. Para no repetir lo ya expresado, nos limitaremos a mencionar una referencia que afecta principalmente a San Lucas, tercer evangelista gnóstico, por cuanto se suele admitir que pudo ser el compañero de San Pablo, cuando Ortega escribe:

[Un rigor] tal que, aplicándolo a cualesquiera otras fuentes ilustres, a Tucídides, por ejemplo, haría imposible intentar la historia de la guerra del Peloponeso. Meyer considera los «Hechos» como segunda parte de una obra histórica, cuya primera porción es el Evangelio de San Lucas. Reconoce en éste al compañero de San Pablo, que la tradición postulaba y hasta acepta su título de médico. ${ }^{42}$

\section{CONCLUSIONES}

Hasta aquí un recorrido por algunas de las citas de los cuatro evangelistas que hemos encontrado en la obra de José Ortega y Gasset. Su erudición y exquisita ecuanimidad hizo posible escribir estos textos sobre autores cristianos de la primera época, resultado de sus numerosas lecturas y de su variado interés intelectual, y escribió con escrupulosa objetividad de temas religiosos como son los extraídos del Nuevo Testamento, a pesar de reconocer en su etapa final que no era creyente.

Sus referencias a filólogos, filósofos, historiadores, pintores de diversos países y épocas, personajes históricos de diversas naciones, pueblos, religiones, oficios, etc. fueron tratados con respeto siempre, con la objetividad y con el rigor científico que siempre ha caracterizado su obra.

Es de agradecer la lectura de estos comentarios orteguianos sobre los Evangelios por su escrupulosa redacción y, aunque en sus años de formación cursara estudios en el colegio de los jesuitas de El Palo (Málaga), nunca expresó un solo lamento por aquella etapa educativa; al contrario, la elogiaba en sus cartas. $\mathrm{Y}$ a lo largo de su actividad docente e investigadora tampoco manifestó un malestar contra lo religioso. Sí afirmó que quiso organizar su vida a su propia manera.

RECIBIDO: agosto 2019; ACEPTADO: noviembre 2019.

${ }^{41}$ El toro se relaciona con Lucas, ya que su Evangelio comienza hablando del sacrificio que hizo Zacarías, padre de Juan el Bautista, a Dios.

${ }^{42}$ OC. 2005; vol. IV, p. 127; en el ensayo «La forma como método histórico». 


\section{REFERENCIAS BIBLIOGRÁFICAS (SELECCIÓN)}

Alonso SchÖKEl, Luis y Mateos, Juan (1977): Nueva Biblia Española, Ediciones Cristiandad, S.L. Madrid [2a edición].

Andenna, G. y D. Tuniz (eds.) (1981): Rodolfo il Glabro. Storie dell'Anno Mille. I cinque libri delle Storie. Vita dell'abate Guglielmo [Tr. it.], Milán.

Cavallo, G. y G. Orlandi (eds.) (1989): Rodolfo il Glabro. Cronache dell'Anno Mille, Storie, Milán.

EUSEBIO DE CESAREA (1497): Historia ecclesiastica, traducción latina de RUFINO DE AQUILEA, P. Levet, París.

OrTEga y Gasset, José (2004-2010): Obras completas, Taurus, Madrid. (10 vol.).

OrTEga y GASSET, José (1991): Cartas de un joven español (1891-1908), edición y notas de Soledad OrTeGA, prólogo de Vicente CACHO VIU, Ediciones El arquero, Madrid, 785 pp.

Pino Campos, Luis Miguel (1997): «Héroes homéricos en la obra de Ortega y Gasset», Revista de Filología 15: 205-220.

Pino CAMPos, Luis Miguel (1998a): «Algunos vocablos castellanos de origen griego interpretados por José Ortega y Gasset», Fortunatae 10: 107-138.

PInO CAMPOS, Luis Miguel (1998b): «Ortega y Gasset y las Humanidades: una propuesta de formación del hombre», Revista de Filología 16: 295-314.

Pino CAmpos, Luis Miguel (1999): «Mundo y cultura árabes en la obra de José Ortega y Gasset», Revista de Filología 17: 613-624.

PIno CAmpos, Luis Miguel (2000a): «Algunos vocablos castellanos de origen latino interpretados por José Ortega y Gasset [I]», Revista de Filología 18: 323-343.

Pino CAmpos, Luis Miguel (2000b): «Interpretación semántica de algunos vocablos en José Ortega y Gasset», en M. MarTínez (y otros, eds.), Cien años de investigación semántica. De Michel Bréal a la actualidad, Ediciones Clásicas, vol. I, pp. 801-816.

Pino CAmpos, Luis Miguel (2000c): La religión en Ortega y Gasset, Biblioteca de las Religiones n. 11, Ediciones del Orto. Madrid, 98 pp.

Pino CAmpos, Luis Miguel (2001a): «Grecia y Roma en José Ortega y Gasset: algunos apuntes sobre su formación y su obra», Revista de Filología 19: 273-288.

Pino Campos, Luis Miguel (2001b): «Raíces griegas y latinas en José Ortega y Gasset. Apuntes sobre su formación, obra y pensamiento", en Actas del C.I. Arte, Educación y Sociedad en Ortega y Gasset... [2000], Fundación José Ortega y Gasset, Revista de Estudios Orteguianos 2.2: $145-157$.

Pino CAMPOS, Luis Miguel (2002a): «Interpretación semántica de algunos vocablos en José Ortega y Gasset [II]», Fortunatae 12: 199-218.

Pino Campos, Luis Miguel (2002b): «Dios en José Ortega y Gasset: una síntesis de sus creencias e ideas», en J. L. CABRIA y Juana SÁNCHEZ-GEY VENEGAS (eds.), Dios en el pensamiento hispano del siglo XX, Ediciones Sígueme S. A., pp. 89-121.

Pino Campos, Luis Miguel (2003): «Presencia del Mundo Clásico en José Ortega y Gasset: algunos aspectos literarios e históricos», Actas del X C.I. de la SEEC. vol. vIII, Ediciones Clásicas, pp. 699-706.

Pino Campos, Luis Miguel (2004a): «Vocablos de origen latino interpretados por José Ortega y Gasset [III]», Calamus renascens. Revista de Humanismo y Tradición Clásica 5-6: 153-176. 
PINO Campos, Luis Miguel (2004b): «María Zambrano, discípula de Ortega», en AA.VV., María Zambrano: Raíces de la cultura española, Fundación Fernando Rielo, pp. 187-308.

Pino CAmpos, Luis Miguel (2005a): «Mito y filosofía: una lectura de la obra de José Ortega y Gasset», Cuadernos del Ateneo de La Laguna 19: 117-134.

PINO CAMPOS, Luis Miguel (2005b): Estudios sobre Maria Zambrano: El magisterio de Ortega y las raíces grecolatinas de su filosofia, S.P. Universidad de La Laguna, 560 pp.

PINO CAMPOS, Luis Miguel (2006a): «Dignidad y resignación en Séneca: algunas reflexiones de Ortega y de Zambrano", en Guido M. CAPPELLI (ed.), La dignità e la miseria dell' nomo nel pensiero europeo, Salerno Editrice, Roma, pp. 323-334.

PINO CAmpos, Luis Miguel (2006b): «El pensamiento hispano del siglo XX y la literatura original: Los ejemplos de Ortega y de Zambrano», en Filosofía y Literatura: Clave de la cultura hispánica, Fundación Fernando Rielo, pp. 79-135.

PinO CAMPOS, Luis Miguel (2006c): «Las ediciones de Idea del Teatro de José Ortega y Gasset: Algunas notas críticas», Revista de Filología 24: 203-214.

Pino CAmpos, Luis Miguel (2007a): «El concepto de mito en la obra de José Ortega y Gasset», en J. A. López Férez (ed.), La mitología clásica en la Literatura española. Panorama diacrónico, Ediciones Clásicas, vol. I, pp. 757-778.

Pino CAmpos, Luis Miguel (2007b): «Los orígenes del Teatro y la filosofía de José Ortega y Gasset», en Ortega en pasado y en futuro. Medio siglo después, Anexo II. 6, Biblioteca Nueva - U. C. de Madrid, pp. 1-15.

PINO CAMPOS, Luis Miguel (2008): «Vocablos de origen griego en la obra de Ortega y Gasset», en J. A. LÓPEZ FÉREZ (ed.), La lengua científica griega: orígenes, desarrollo e influencia en las lenguas modernas europeas, vol. II.1, Ediciones Clásicas S.A., pp. 167-277.

Pino CAmpos, Luis Miguel (2009a): «En torno a Idea del Teatro de José Ortega y Gasset: Aportaciones y nuevas consideraciones», Revista de Filología 27: 123-137.

PINO CAMPOS, Luis Miguel (2009b): «Dioses y personajes míticos en la obra de José Ortega y Gasset», en J. A. LÓPEZ FÉreZ (ed.), Mitos clásicos en la Literatura española e iberoamericana del siglo XX, vol. I, Ediciones Clásicas, pp. 123-140.

PINO CAMPOS, Luis Miguel (2009c): «El magisterio de Ortega en los epistolarios de Zambrano: las Cartas de La Pièces, Javier ZAmora (y otros, eds.), La audacia de la libertad. Homenaje a Agustín Andreu, U. Politécnica de Valencia, pp. 341-370.

PINO CAmpos, Luis Miguel (2009d): «Ortega en la obra de Julián Marías: el ejemplo de Una vida presente, en A. Pérez Quintana y L. M. Pino CAmpos (eds.), Una vida presente: estudios sobre Julián Marías, U. La Laguna, pp. 67-124.

Pino CAmpos, Luis Miguel (2011): «Ortega y la ética de los griegos», L. M. PINO (y otros), Ética y Literatura contemporáneas en tiempos de encrucijada, Fundación Fernando Rielo, pp. 13-42.

Pino Campos, Luis Miguel (2012): «Filología y Lingüística en José Ortega y Gasset. A propósito de El pensamiento lingüístico de Ortega, de Concha D’Olhaberriague», Philologica Canariensia 18-19: 1-16.

Pino CAmpos, Luis Miguel (2013): «Poetas griegos en la obra de José Ortega y Gasset», Actas del C. I. José Ortega y Gasset: Nuevas lecturas, nuevas perspectivas..., Fundación José Ortega y Gasset, 1-15.

PINO CAmpos, Luis Miguel (2014): «Poetas griegos en la obra de José Ortega y Gasset», REO (Revista de Estudios Orteguianos) 28: 131-157. 
Pino Campos, Luis Miguel (2016a): «Pericles en la obra de José Ortega y Gasset», Fortunatae 26: 107-126.

Pino CAmpos, Luis Miguel (2016b): «Atlántida y Atlántidas: reflexiones de José Ortega y Gasset», en Fronteras entre el verso y la prosa en la literatura helenistica y helenístico-romana. Homenaje al profeor José Guillermo Montes Cala, vol. I, Collana di Studi e Testi. Studi 62,. Levante editori, Bari, pp. 567-593.

Pino CAmpos, Luis Miguel (2017): «El Cristianismo en la perspectiva de José Ortega y Gasset», en Pablo de Paz Amérigo e Ignacio Sanz Extremeño (eds.): Eulogía. Estudios sobre cristianismo primitivo. Homenaje a Mercedes López Salvá, vol. 1, Guillermo Escolar Editor, Madrid, pp. $495-514$.

Pino CAmpos, Luis Miguel (2019): «Aspectos de Tradición Clásica en algunos filósofos de la Escuela de Madrid: Ortega, Zubiri, Zambrano y Marías», en J. A. López Férez (ed.), La Tradición Clásica en la Literatura Española e Iberoamericana del siglo XX, Ediciones Clásicas, pp. 1-35.

PINERE, Antonio (2006): Guía para entender el Nuevo Testamento, Editorial Trotta, Madrid, 568 pp.

PIÑERo, Antonio (2009): Todos los Evangelios, Edaf, Madrid.

QUINTERO, Juan Pablo (2016): «Apuntes sobre la Esteganografía de Trithemius», Revista Nova et Vetera 1 (2) [marzo], Universidad del Rosario [en línea; acceso: 09/12/19].

RUFINO DE AQUILEA (1978): The epigrams of Rufinus, edited with an introduction and commentary by Denys Page, Cambridge University Press, XII +115 pp.

Rufino de Aquilea (1968): Les bénédictions des Patriarches. (Rufin d'Aquilée), introduction, texte latin, notes et commentaire par Manlio SimONETTI; traduction de H. ROCHAIS; revue par P. Antin, Colección Sources chrétiennes 140, Ed. Du Cerf, París, 164 pp.

Souza de MendonçA Júnior, Francisco de Paula (2016): «A poligraphia de Johannes Trithemius: reflexões acerca das relações entre Esoterismo e política nos séculos XV e XVI», REHMLAC 8 (1) [may.-nov.]: 1-23. 